



\title{
ART WORK
}

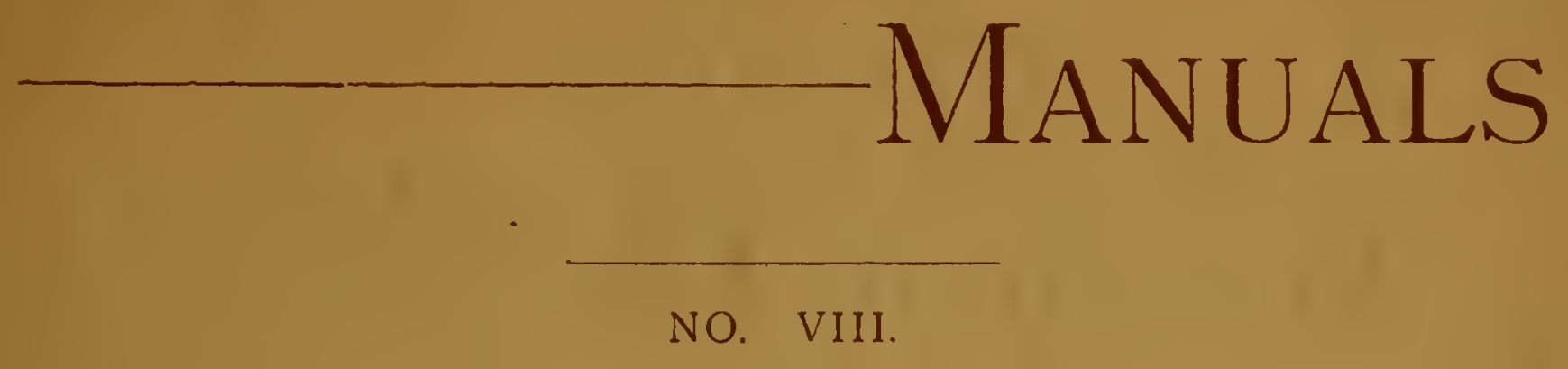

REPOUSSÉ WORK

EMBOSSING ON SHEET BRASS

WITH ILLUSTRATED SUPPLEMENT

\author{
Edited вy CHARLES G. LELAND \\ Director of the Public Art Schools of Philadelphia \\ Author of the "Minor Arts," etc.
}

PRICE, THIRTY-FIVE CENTS.

NEW YORK

The Arti Interchange Company william ivhitlock, Publisher

ifo Nassau Street 
They are Absolutely Perfect.

No School is Complete without them. No Studio is Furnished witbout them
They are unequaled for Technical Draning.

Make Finer and more Perfect Lines.

Greater Variety of Shadiag for Art Work.

Leads are Black, Smooth, Strong, Pleasant.

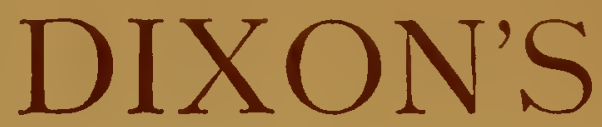

American Graphite

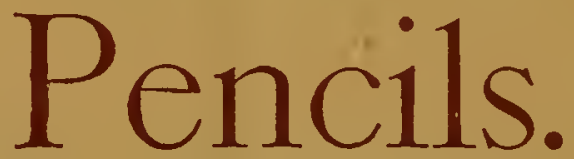

TEN QRADES OF LEADS, AS FOLLOWS, VIZ.: Similar grade to the European stamp of

VVS-Very, very soft....(B B B)

VS-Very soft.......... B B)

S-Soft .............. B and No. I)

SM-Soft medium......(H B and No. 2)

MB-Medium black....(F)

M-Medium.......... (H and No. 3)

MH-Medium Hard.....(H H)

$\mathrm{H}-\mathrm{Hard} . . . \ldots \ldots . . .(\mathrm{H} \mathrm{H} \mathrm{H}$ and No. 4)

$\mathrm{VH}-\mathrm{Very}$ hard......... (H H H H and No. 5) VVH-Very, very hard...(H H H H H

nsese pencils are superior to any made in Europe. The leads are much finer, smoother, and more perfectly graded. The hard grades are perfect for architects, draughtsmen, and engineers, and the softer and merlium grades are unequaled for art work.
TESTIMONIALS.

Dear Sir:-I find the Dixon Graphite Artists" Pencils admirable; well adapted to clear, sharp, and delicate cils admirable ; well adapted to clear, sharp, and delicate
work. Pres. Nat. Academy of Design, N. $\dot{Y}$. Am. BANK Note Co., Art Depart., N. Y.
From a careful trial now of several months, I am perfectly satisfied they far exceed any I have ever used.

Very respectfully yours, WILLIAM MAIN SMILIE.

Dear Sir :-I find your Dixon American Graphite Artists' Pencils smooth, free from grit, and altogether excellen or my work. Vours obediently

FRANK BELLEW, Nat. Academy of Design, N. I.

Packer Collegiate Institute, Brooklyn.

Sister and myself, in teaching our Drawing Classes, use your Dixon Pencils, and we prefer them to any other. VIRGINIA CRANBERRV Teacher of Drawing, Packer Institute.

Dear Sir:-Your very excellent pencils, stamped Dixon's American Graphite Pencils, substitute the $e x$ hausted mines of Barrowdale in Cumberland. Your Artists' Pencils are in strength and sinoothness the best 1 ever had in $\mathrm{m} y$ hand. Jours truly,

Prof. of Drawing, Polytechnic Institute, B'lyn, N. Y.

\section{Samples worth double the money will be mailed free for 25 cents.}

JOS. DIXXN CRUCIBLE CO., FERSEY CITY, N. $\mathcal{F}$ 


\title{
Repoussé Work or W \\ EMBOSSING ON SHEET BRASS
}

\author{
EDITEd by CHARLES G. LELAND, \\ Director of the Public Industrict Art Schools of Philadelphia; \\ Author of the "Minor Arts," eti.
}

Art Work Manuals

NO. VIII.

ILLUSTRATED WITH SUPPLEMENT.

NEW YORK.

The Art Interchange Company, I 40 Nassau Street. 
女

LIBRARY OF THE

COOPER-HEWITT MUSEUM OF DESIGN

- SMITHSONIAN INSTITUTION . 


\title{
Repoussé Work or \\ EMBOSSING ON SHEET BRASS
}

\author{
EDITED BY CHARLES G. IELAND, \\ Director of the Public Industrial Art Schools of Philadclphia; \\ Author of the "Ifinor Arts," eti.
}

Art Work Manuals

NO. VIII.

ILLUSTRATED IVITH SUPPLEMENT.

NEW YORK.

The Art Interchange Company, 140 Nassau Street. - 



\section{REPOUSSÉ WORK.}

OR EMBOSSING SHEET BRASS.

$R^{\mathrm{E}}$

EPOUSSÉ work is a term applied to sheet metal in which ornamental patterns are "pushed out," that is to say, raised in relief, by hammering or otherwise indenting the sheet. It is also called, in its variation or degree, embossed or chased work. It is produced in two ways, firstly, by stamping with a metallic die or mould, generally worked by a steam-engine. It is needless to say that the result of such machinery-facture, however beautiful it may be, has no more claim to be called a work of art, than has anything else similarly ground out in exact duplicate, and bearing no trace of direct human touch or expression. Work which much resembles repousse' is also made by casting in moulds; but though many people confound them together, they are altogether different.

Repoussé work is chiefly effected by a punch and hammer. The punches are implements very much resembling large nails without heads. A skilful workman can, in fact, make very preity work with a common nail. I have seen, in Nubia, silver bracelets or bangles which had been made in the interior with only a nail and a stone for a hammer; and though the work was not finished like the machine-made jewelry of this country, it was still artistic and characteristic. Castellani, the greatest living connoisseur in jewelry, and the author of several works on it, earnestly declares that the coarse ornaments made by peasants in Italy have a far highor artistic charm than the most elaborate and costly triumphs of machinery which one sees in the windows of the Palais Royal. The author has in his possession a large silver bangle which has been much admired, and which was worked with a point de Paris, or common round French nail. In a word, the reader may bear in mind, as regards every kind of decorative work, that the hand-made in art, when there is any degree of skill, has a certain value of its own, and a peculiar merit, which disappears with every artificial improvement in the manufacture. For it is as the work of man. 
and as bearing the impress of a mind and of an individual, that art work is properly interesting; and this conviction or feeling is so greatly on the increase, that there can be little doubt that we are gradually approaching an era when it will be the true standard of excellence. Should it once be universally established, decorative art will become as real as it is now soulless; there will be infinitely greater interest taken in it, as was the case in classic times and during the Middle Ages; and it is very probable that the majority of those who are now idle will then be able to find profitable employment. For it cannot be denied that machinery, while it has added enormously to the average comfort of the world, has, for a time at least, not only deprived the daily art of life of nearly all interest, but also benumbed or destroyed the tendency to create an interest in art in minc's which are peculiarlyfitted for it. Sheet-brass work is very easy. In its simpler stages, $\mathrm{where}$ only very thin and ductile metal is employed, the art can be practised by any amateur who can draw a pattern.

There is a very general impression that to work in sheet brass must be very dif ficult. It seems like blacksmithing, and quite unfit for ladies. But if a lady will take a piece of the thinnest sheet brass, she will find it so soft and pliable that she can indent or draw a pattern on it with a wooden stick, or even make a deep indentation with the point of her finger. If she will lay it in a hollow, saucer-shaped place, cut in a board, she may, by gradual and equal hammering with a mallet or rubbing in of all parts, easily form it into a hemisphere. There is a machine by which a sheet of brass is instantaneously "spun up" into a kettle or any kind if "hollow-ware." Now, if a piece of thin sheet brass be laid upon, or le backed by some substance which only yields to hard pressure, it is evident that it can be $\bar{n}$ o difficult matter to indent patterns in it. The thinner the sheet the easier the work; but those who have once indented a pattern on thin metal, can do it just as easily, on a second trial, on a sheet a little thicker, and so on. Brass is sold by a pattern in about 30 thicknesses. But even if you design a pattern on a solid piece an inch thick, you will find it a very easy matter to beat a pattern on it with by no means very violent blows of a hammer.

Sheet brass costs at retail about thirty-five cents a pound. Let the beginner take a piece, say of No. 25 , and design a pattern on it with a black soft pencil or with ink. Or it may be drawn on thin paper. Then lay a sheet of transfer paper on the brass, and the design on this. Then with an agate point. or one of bone, or even with a very hard leadpencil, carefully trace the pattern. Too great care cannot be exercised in this tracing. I believe it is Camille Piton who has said that it is even harder to trace accurately than to draw; and he is quite right. Ladies should not suppose, because they have traced many patterns for needlework or for porcelainpainting, or any kind of tlos ers, that they are on that account perfectly qualified to trace on brass. In the needlework a false line is easily corrected; in flowers few 
blunders are supposed to be perceptible; hence any variation makes but little difference, the general result being that flower-painting, as commonly pursued, induces much inaccuracy and shiftlessness, both of observation and design, and is the last branch of art which the young should ever be allowed to take up. In working on metal, every blow struck leaves an indelible impress-litera scripta manct-and it is almost impossible to correct an error.

Before proceeding to work up a pattern, let the beginner take a piece of waste sheet brass. - Then holding in one hand the tracer, or, as some call it, the bordering tool or borderer, and putting the edge of the latter on the metal, give its other end a light tap. There will result a mark like __, or ........, according as the edge has been made like that of a scre $x$-driver, or serrated. Preferably it should be the former. Now pass the tracer along tapping its top as you run it until you shall have made a long and perfect line; so perfect indeed that no one can distinguish any place in it where the tool was taken up. This is all-important. After a fe $v$ trials you will find your line improving. That is always miserable work in which there are dents, breaks, and irregularities in the outlines; yet there are very few pupils who, if left to themselves, will not make them, in their eagerness to produce something to show. Most pupils invariably expect to make something astonishing at the first effort. Nothing can interfere more with real progress or taste than such childish impatience. When the pupil can trace an even and accurate line, and not before, he or she may proceed to work a patterr,; Take the sheet brass, with the design, and look it over carefully. If there is the least error, rub it out and correct it with a pencil or ink. Do not rely on making corrections with the tracer. What seems like a trifling fault in the drawing, will look bad when impressed in metal.

Now lay the brass on a block of lead half an inch thick, and with a tracer or borderer, and with a chaser's hammer, made for the purpose and to be obtained through any jeweler or hardware dealer, mark the outline as lightly as possible. Bear this in mind. It should be so light as to be barely perceptible, especially in very thin brass. If you cannot obtain the leaden blocks, take a smooth board. Lay the sheet as level as possible, and fasten it down with screws, for each of which a hole may first be made with a round nail and hamıner. Having drawn the pattern outline it with the tracer. As I said, this must be done r'ery lightly at first. If you begin by hammering in deep hollows and furrows on one side of the pattern, while there is no indentation on the other, you will make the pattern "buckle," that is, bend the lines into awkward shapes, inclining to one side or the other During the progress of the work it must be outlined at least two or three times.

When you shall have got the design with the tracer, take a mat or punch with a broad end, and hammer in the background between the patterns, and going over the whole design at the base of the patterns. To do this perfectly, you should have one mat not more than an eighth or tenth of an inch in diameter at 
the end. This ena, which marks the metal, is roughened or marked uith very fine crossed lines like a seal. The tools can be easily made, by any person accustomed to work in metals, from the steel rods sold for the purpose; many dealers keep them ready made. They are endless in variety, as all workers in metal constantly need some new pattern. In England they cost from $6 d$ to $9 d$; in the United States, from twenty to thirty cents. As you work on, at the background, you will

find that the pattern rises more and more, and with labor this relief may be greatly increased. The greatest care must be taken not to break through, crack or make holes in the sheet This is to be avoided by tracing at first very lightly, and going over the tracings carefully, especially when "culd hammering" or working without annealing. The process is similar to wood-carving. After becoming familiar with the process as I have described it, the pupil should learn to hammer by holding the sheet in one hand instead of screwing it do $\mathrm{n}$. It is needless to say this is rough work, but the result will be quite equal to that of the fifteenth century platters or plaques, which are much admired, or even to that of many of the pretty Algerine bangles which are so much worn. If you will obtain a brass plaque for a pattern - and they can be had through the ART INTERCHANGE-you will find it very easy to copy. With a plaque and tools and brass, any child can produce a very pretty fac-simile.

Rings, semi-circles, diamonds, or any curves may be made in brass, by using punches on which they are cut. But the first object of the pupil should not be to produce something pretty or to show, but to become familiar with the metal and the effects of tools upon it-in brief, to become skilful. With the great majority of pupils, young or old, the impatience to produce something which shall astonish their friends as soon as possible, and, if possible, at a first trial. leads to wretched results. They take no pains in the beginning to learn to draw or transfer patterns; and, after this, still less to learn to outline and ground skilfully on trial-pieces of metal before undertaking what is fondly hoped will be a chef d'eenere. Let me impress it on the mind of the reader attempting to learn a minor art, that, unless he or she is entirely thorough and careful at the commencement, it will be idle to hope to learn. The plaque which is carelessly dented and tinkered into shape, when polished up will doubtless seem very wonderful to admiring friends, and be prondly exhibited; but after awhile the worker will not fail to find out that it is worthless, and become disgusted with the art Careless habits acpuired in the beginning are seldom laid aside. When you have learned to work well, you will have abundant opportunities. Df the thinnest sheet brass you may make pretty panels, which may 
he tramed in cabinets, set in boxes, used as strips by the sides of fireplaces, in bellows, or used as "finger-plates" on doors. Any one, who will devote a few days to learning how to work very carefully on waste brass, can then make a great variety of very beautiful and useful objects.

There is a very expeditious method of embossing sheet brass or any other metal used by the regular workman. It consists of an elastic rod or spring, which is set in motion either by a treadle or by the left hand. It taps on a hard

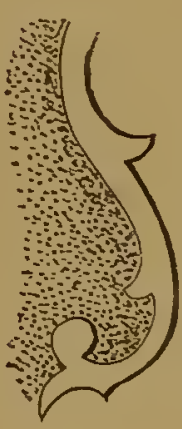
surface, between which and the hammer the sheet metal is introduced. The apparatus can be obtained through any brassworker or chaser. But before using it, I recommend that a perfect familiarity with the punch and hammer be acquired. I have said that the thinnest sheet brass should be used at first. This may be worked up very prettily for small objects with only a tracer or border-tool and a simple round French nail, the point of which has been dulled by rubbing it on a stone sufficiently to keep it from piercing the brass. This will produce a dotted background.

If you take sheet brass of the thickness of a playing-card, or, better, somewhat thicker, e. g., No. 25 ,

cut it into a strip of about 4 inches by $\mathrm{I} 2$, and turn three inches at one end horizontally, you will have the basis of a sconce, or hangung candlestick.

Hammer the pattern in the sheet, punch out a small round hole to hang it by, and get the tinman to solder a socket on the projecting portion to set the candle in. These reflectors can be made oblong, round, or oval. Sheet brass is easily cut by means of a fret or scroll saw. If you understand the use of it, you can cut brass one-eighth of an inci in diameter. This can be applied $t$ ) a great variety of very elegant work, such as false hinges for chests and cabinets, scorces in the form of birds and pictures, or mirror-frames. If a sheet of metal is thus sawn out, and placed on velvet, the effect is very fine. If the velvet be stretched on a frame, and the brass so contrived that the velvet may be taken away and easily replaced, it will be much better, since it may then be scoured from time to time.

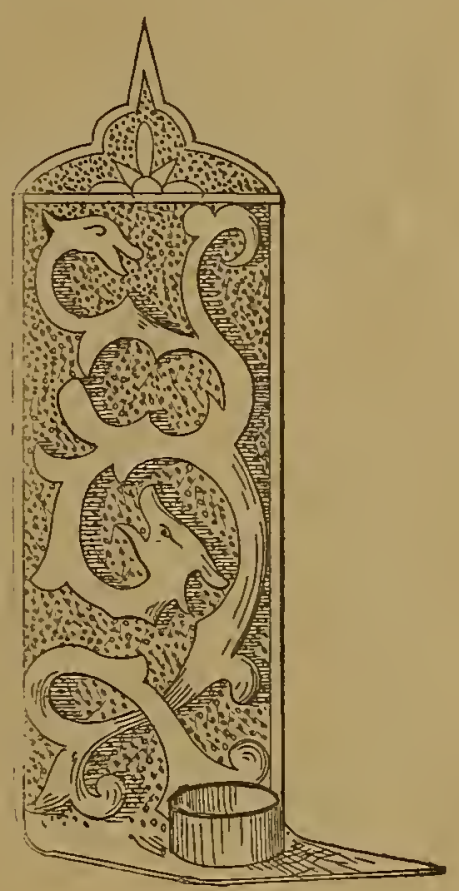

After trying a number of highly recommended appliances, I have found that on the whole the best means of polishing brass is to take rotten stone or tripoli and turpentine to begin with, and then to finish 
with oil and chamois skin. There may be other equally good methods. Oxalic acid produces a bright surface at once. A brass plaque or platter, of about 16 inches diameter, is a very favorite subject for work. The pupil is urged to avoid in the beginning designs which contain inside lines, that is to say, feathers in birds, the ribs in leaves, eyes in animals, scales in fish, or the lines in their fins and tails. Very bold and effective patterns may be designed without any of these. Birds, fish, and arabesques, simply outlined and beaten out, are very striking. In sheet brass work the best effects are those of full, broad, and round shining surfaces, such as reflect the light and catch the eye in the demi-jour or twilight of a drawing-room. Therefore the old sheet brassworkers often made knobs, round, projecting, hemispherical fruits, and bunches of grapes. An ignorant amateur is invariably fond of petty work in all the minor arts, and of making elaborate little effects which require close inspection. This tendency to pettiness and detail should be guarded against in every way. It is very easy for the decorative artist, accustomed to working in a bold manner, to descend to elaboration, for the greater includes the less, but it is almost impossible for the petty workman to rise to bold work. There were petit-maitres, like Mieris and Terburg, among the scholars of Rembrandt, but no petit-maitre in art ever had a Rembrandt among his scholars.

Deep Chasing.-You will, as you use thicker sheets, wish to hammer sometimes fron the back, into the raised patterns, either to produce a deeper relief, or to smooth and correct inequalities. For this purpose you must make a bed of so-called pitch or composition, which, when hard, yields only gradually under the hammer. You have already learned that, in hammering on a soft pine board, it was necessary to work on some basis which resisted while it yielded. But the fibrous structure of the wood only permits a certain degree of yielding. To obtain a deep relief, something must be used, which, while it resists somewhat, or is difficult to penetrate, must also be gradually penetrable to almost any extent. For this purpose make a bed of brick dust or plaster of Paris, fine sand or ashes, or even dust, which is to be thoroughly well mixed with pitch (or resin), in equal parts with the dust, and a iery little tallow or turpentine. 'Those who supply jewelers' tools generally keep this composition for sale, at twenty-five cents a pound, in cakes. When the brass is laid on a bed of this, it can be indented very easily on either side, and by turning alternately. If you have a sheet brass or thin slver cup or plate, or goblet, or salver, you can fill it with the melted pitch, or "back it," and can then work easily on the outside. If you wish to raise a bunch of grapes an inch or two inches, you must hammer them out from the inside, and then, to finish the work, turn it again, and execute the mrire delicate parts from the outside.

Fuxing. - Many persons prefer to "fox," or stick every article which is to be chased, on the pitch-block. This is a block of wood or iron of about eight inches 
in diameter, which rests on a ring of leather or straw. Its top is covered with pitch, which is warmed whenever a new article is pressed into it. All who work beyond the mere rudiments will come to using the pitch-bed and eventually to foxing. In this work I propose to deal only with the rudiments of sheet metal, as they may be most easily and cheaply acquired by mere beginners. Any one who carefully acquires the rudiments of any minor art-and this may be done perfectly from any of these ArtWork Manuals--will find it easy to advance. It is not with them as with the so-called fine arts of picture and statue making. So long as decorative art is kept within its legitimate limits, that is to say, to the beautifying the useful, it is never difficult. But when any object is adorned in such a manner as to be practically useless, it is no longer decorated, but becomes a mere decoration of itself. It would be far better for the world, for taste and for culture, if, for many years to come, genius would let mere decoration alone, and apply itself to combining the useful and the beautiful. If there could be no picture or statue making for a decade, the result would be better pictures and statues than are now made, for what is now wanted is a general and popular intelligence of the beautiful, and this will only come through the general dissemination of decorative art.

ANNEAling, - It is advisable, after preparing the bed of pitch, to give it the thinnest possible coat of oil. This causes the metal to work better on it. If there is too much oil it will not adhere. It is often necessary in heavy metal and in working deep relief to anneal the work. This is effected by placing it in an oven bed of coals till it becomes soft-not in the least melted, however - and then removing it very carefully with pliers or pincers. It was with such pincers', usually confounded with tongs, that Saint Dunstan,

\footnotetext{
"As the story goes,

Once took the devil by the nose,"
}

while the Saint was annealng metal. Whoever has annealed knows how vexing it is to be interrupted just at the critical moment, and the Evil One, knowing this, chose that time to provoke the Saint into unsaintly anger. Saint Dunstan, or: as the French say, Saint Eloy, instead of giving way to wrath, calmly took Satan by the nose, drawing it out to the great length which it has since had, and destroying the last trace of beauty in the fallen angel. The story was intended to teach all workers in brass and other metals, that they must be very patient, especially in annealing. Annealing oxidizes and softens the metal While hammering cold sheet brass, the oft-repeated blows harden the metal and cause l rittleness. This brittleness is removed l.y annealing, which restores the original ductility or softness. After working, the metal must Le cleaned $1 \mathrm{y}$ boiling it in sulphuric acid, mixed or diluted with from six to twelve parts of water. With thin sheets of good metal, annealing for 
amateurs will not be necessary when making basso-relier'o, or very low relier. Do not forget that, tefore applying the metal to the pitch, it should be warmed and very slightly oiled, the oil being then rubbed off.

The lady amateur will find that the easiest object to make is a candle sconce or a brass finger-plate for a door, three inches broad by seven or eight inches long. It may te ma je with the thinnest brass, with only a nail, which is really easier work than modelling in clay. When the finger-plate is finished, any worker in metals will mount it for you, in a narrow, strong, thin 1 rass frame, in whirh there should be holes made, through which the screws pass which fasten it to the door.

Let us now describe distinctly in full the process by which a plaque or plattercommonly used during the fourteenth and fifteenth centuries for fruit and serving wine -is to be made. Obtain a square of sheet-brass, 16 inches by 16 . You may begin with No. 25 ; but for practical use the platter should be much thicker, let us say, oneeighth of an inch in thickness. Get a board at least an inch, of soft white pine, and let this be at le ist $\mathrm{I} 7$ inches by $\mathrm{I} 7$. Now take a strong, coarse, very stiff pair of carpenter's compasses and describe a circle exactly 16 inches in diameter. Then within this inscribe another circle of $14 \frac{1}{2}$ or 15 inches diameter. The space betw een this latter and outer circle is to be in all cases left plain. It is to be turned over to inclose a wire when the plate is to be made up by a tinman. Then draw with great care your pattern. Now take the square piece of brass and screw it to the board, taking care that no screw goes inside the circles, but that they are to be at the corners. Strange as it may seem, all beginners, old or young, never reflect that a screw-hole in a plate is a blemish, and invariably begin by putting them within the outer circle. Great care must be taken to prevent the brass from buckling or bending up. When all is ready, proceed with the work as before described. When it is finished, take out the screws and give the square piece of brass to a tinman. $\mathrm{He}$ will cut it round and put a wire round the edge, turn the edge over, and affix a ring to hang it up by for twenty-five cents. Then polish it carefully. When not in use and hung up, this plaque or platter may be placed in a velveteen frame of three or four inches breadth, which gives a fine effect. In like manner the sides of a pair of bellows may be very easily made. A clever lad, who is a good and careful workman, can make by hand a really beautiful and well-finished plaque of 16 inches diameter in from three to four hours. To do this it is necessary that the pupil shall have made a perfectly careful and thorough beginning, have acquired a very accurate manner of work, and work only from a well-drawn pattern.

There are more elaborate and artistic methods of metal work practised and far more advanced processes; but I have limited my description of both processes and instruments to the simplest, for the sake of encouraging the beginner. If the pupil chooses, he or she may now make a silver bangle-bracelet. Let us begin with a simple, flat circlet, like a napkin-ring. Take a piece of wood about the size of a 
lady's wrist, and such that the bangle may slip very lnosely over it. Wrap newspaper or leather around this very smoothly, so that the bangle may fit tightly, or else pitch it. Or the bangle inay be worked flat on wood or pitch, and then made up by a jeweler. This is not a scientific method of working, but it is easy for amateurs, particularly ladies, who have few resources and who cannot manage pitch. Silver is tougher and harder than brass, but finer in quality, and it is in the end the most agreeable material to manage. Very pretty charms may be cut with a hand fretsaw from sheet silver. They form very acceptable presents to most ladies. With all your care in bangle-making, you will, if you do not anneal the metal, break it in a few places at first or make some holes. These the silversmith will solder up for you, until you learn to do it for yourself. Should the bangle, as it wears, grow blackish in the ground, do not remove it, but polish the pattern in relief as much as you please. This will produce a niello-like relief, and cause it to shine more in a strong light by night.

The art of engraving silver is not difficult to acquire in its simpler stages. The tool used, which resembles a wood-engraver's cutter, is held and guided in most positions as in wood-carving, and two or three days' practice on a zinc block, or on the back of a piece of stereotype plate, will enable anybody to cut ordinary curved lines with tolerable accuracy. A few of the simplest ornaments, dots and lines, will add very much to the effect of a silver bangle or of brass work. The art may be said to consist in, firstly, running a straight line or groove in the metal with perfect accuracy and confidence; if you can do this with a pen and ink or with a leadpencil, you can soon do it with a graver. Secondly, you must learn to gradually deepen the line, and then make it lighter, and, when this art is acquired, to do the same in curves and twists. This bending is more difficult, but with it the main difficulty in common line engraving ceases. There are few towns in which some one cannot be found to teach metal chasing and engraving.

If the pupilintends to work seriously at this elegant art, he should learn to make his own punches. Let him buy, at a tool-shop, some of the square steel rod or wire made for this purpose-say, a piece three feet long by one-eighth of an inch square-and divide this with a triangular file into nine equal parts. Thin both ends of each part a little, as shown in the preceding cut of a punch, and file one end into the shape required for the work in hand, i.e., into a square, a convex surface, a straight tracer, edge like that of a dull chisel, or very dull gouge, a diamond, a ring or crossgrooves, as it may be wanted; harden this end by heating it in the yellow part of a gas flame, and dip it into oil or water when yellow hot. The punch will then be ready. With a little practice you may make perfect tools. Many of these are also useful in leather and wood-work and in modelling clay. It is often impossible to find what you want in shops. 
ETCHING METAL. - Brass or silver or steel may be easily etched-i.e., eaten into by acids. It is a vulgar error, as Hamerton has shown, to call a pen-drawing an etching. It is from the German actzen, to eat into or corrode. Cover the metal with varnish; let it dry, and then draw your pattern with a sharp point-say, a needle-simply removing the varnish and exposing just so much of the metal as you wish to show black lines. Put strips of wax round the metal, and then pour on it a mixture of one part of acid to three of water. Brush away the bubbles, as they gather, with a feather, or the lines will be very ragged. Then pour out the acid and water, and wash away all the varnish with turpentine. Then you will find your drawing engraved on the shining surface. Or you may coat the bracelet or brass plate all over, back and front, with varnish, and put it into a cup or soup-plate full of the diluted acid. Add acid in proportion to the hardness of the metal.

Pewter and tin may also be worked with good effect. A pewter tankard or plate is easily cast, and, when cast, may be worked with the same tools as brass. Type metal is also applicable to much decorative work. It admits of being admirably engraved and chased.

Charles G. Leland.

[Students and anatcurs can have any difficulty which they may encounter explained and obviated in the columns of THE ART INTERCHANGE, withont charge, by addressing the Editor of the Notes and Queries Department.] THE ART INTERCHANGE, I 40 Nassau Street, N. Y. 
FOR

\section{$\overline{\overline{R E P O U S S E}} \quad$ WORK $\equiv$}

OR EMBOSSING ON SHEET BRASS.

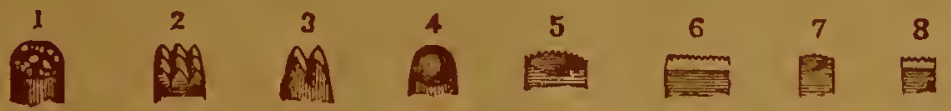

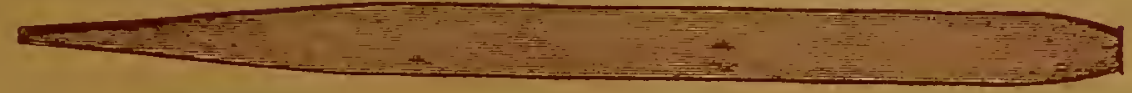

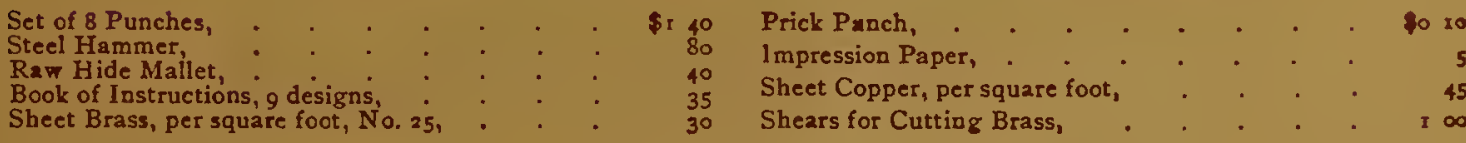

Sheet Brass, per square foot, No. 25, $\quad 30$ Shears for Cutting Brass,

A COMPLETE PORTFOLIO of 48 DESIGNS in an Tmitation LEATHER CASE, by mail, \$r.50.
All Designs, I5 cents each.

We have on hand all styles of TRACING TOOLS, any width; also all tools for Matting or Background work. Price each, 20 cents. SPECIAL TOOLS made to order of any design at short notice.

\section{PETER A. FRASSE \& CO.,}

P. O. Box 54 .

95 Fulton Street, Nerw York.

We have a complete assortment of WOOD-CARVING TOOLS, LATHES, FILES, and STEEL suitable for amateurs.

\section{REPOUSSÉ SUPPLIES}

EMBOSSING AND HAMMERING SHEET BRASS PANELS, PLAQUES, COATS OF ARMS, HERALDIC EMBLEMS, MONOGRAMS, FIREPLACE BORDERS.

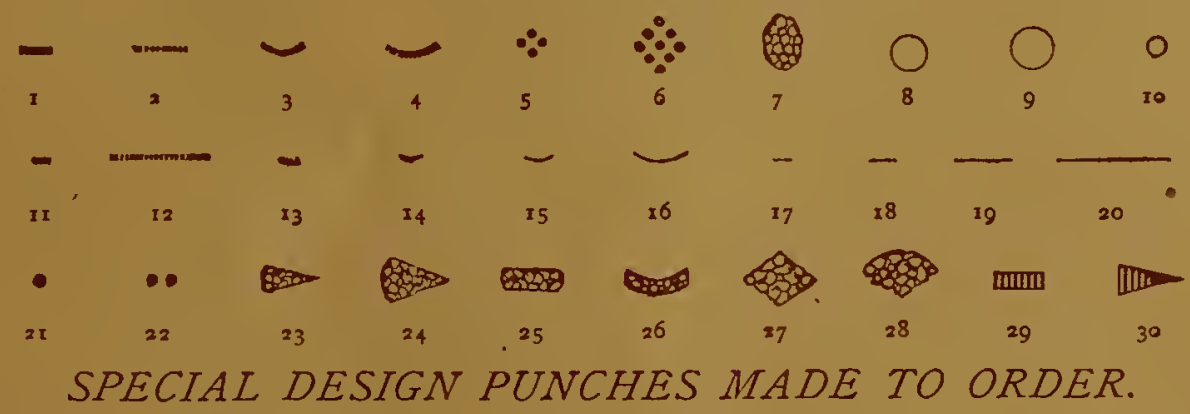

Set of 8 Punches, boxed,

Shears for cutting metal,

Steel Hammer,

Bool of Instructions, with Designs,

Sheet Copper, No. 23, per sq., $12 \times 12$ in.,

Sheet Brass, No. 26 , per sq.. $14 \times x_{4}$ in.,

\section{MONTGOMERY \& CO.,}

IMPORTERS OF

STUBS' FILES, TOOLS AND STEEL, GROBET SWISS FILES, CHESTERMAN'SMEASURES, HUBERT'S FRENCH EMERY PAPER, HORSESHOE MAGNETS, \&C.; WM. SMITH \&०

SON'S CELEBRATED MUSIC WIRE, NOS. 2 to 30; FRENCH SHEET STEEL, $31-4$

in. wide, from 4 to 65 thousandths; MACHINISTS', SILVERSMITHS',

ҰEWELERS', DIE SINKERS' AND ENGRAVERS' SUPPLIES. 


\section{REPOUSSE}

TOOLS, MATERIALS, AND DESIGNS.

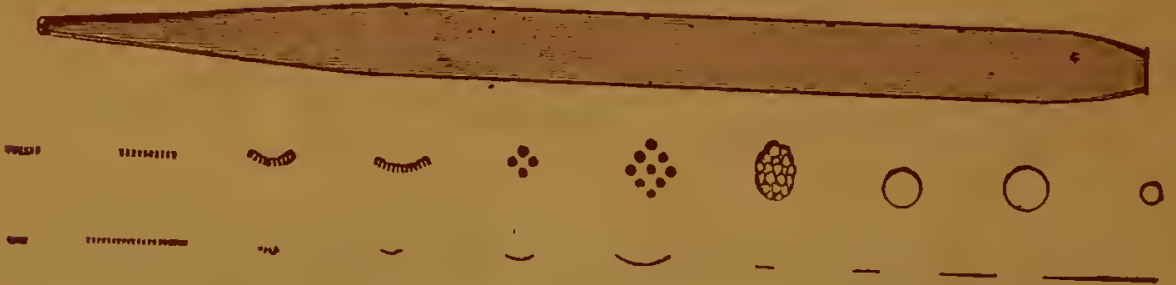

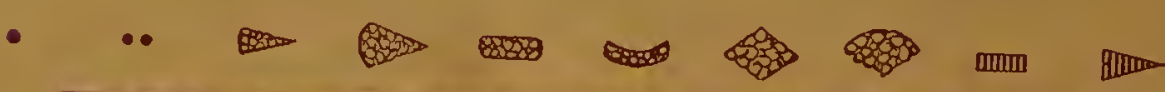

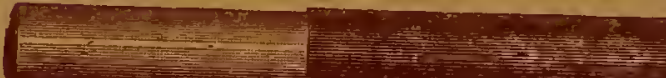

$\left\lfloor\frac{1}{8} \quad \frac{3}{16} ! \quad \frac{1}{4}\right\rfloor \quad \frac{5}{16} \quad-\frac{3}{8}$ Being Manufacturers of Tools and Publishers of Designs for the above work, we are prepared to
furnish them in large or small quantities at the lowest market rates.

COOD NOST SENT UPON APPIICATION.

GOODNOW \& WIGHTMAN,

Frost \& ADAMS

76 Washington St., Boston, Mass.

-37 CORNHILL, BOSTON

IMPORTERS OF

ARTISTS' MATERIALS

OF EVERY DESCRIPTION,

ART NOVELTIES FOR DECORATING,

- Tools and Materials for Repousse Work a Specialty.-

SPECIAL ATTENTION IS CALLED TO OUR LINE OF

Studies in Oil, Water Color, Charcoal, Crayon, Etc., Etc.

Illustrated Catalogue sent upon application.

The above goods, together with a complete line of Fine Station-

ery, can also be found at our Branch Store,

A. A. WALKER \& CO.,

538 W ASHINGTON STREET, BOSTON.

OPPOSITE HIJOU THEATRE. 
SMITHSONIAN INSTITUTION LIBAARIES

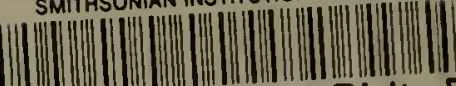

39088002763640

Repouss:e work or embossing on sheet bra 